University of Nebraska - Lincoln

DigitalCommons@University of Nebraska - Lincoln

$7-2012$

\title{
Emergent Interfacility Evacuation of Critical Care Patients in Combat
}

Yvonne E. Franco

C.R. Darnall Army Medical Center

Robert A. De Lorenzo

Brooke Army Medical Center, Robert.DeLorenzo@amedd.army.mil

Steven W. Salyer

Brooke Army Medical Center

Follow this and additional works at: https://digitalcommons.unl.edu/usarmyresearch

Franco, Yvonne E.; De Lorenzo, Robert A.; and Salyer, Steven W., "Emergent Interfacility Evacuation of Critical Care Patients in Combat" (2012). US Army Research. 194.

https://digitalcommons.unl.edu/usarmyresearch/194

This Article is brought to you for free and open access by the U.S. Department of Defense at DigitalCommons@University of Nebraska - Lincoln. It has been accepted for inclusion in US Army Research by an authorized administrator of DigitalCommons@University of Nebraska - Lincoln. 


\title{
Emergent Interfacility Evacuation of Critical Care Patients in Combat
}

\author{
Yvonne E. Franco, DSc, APA-C, ${ }^{1}$ Robert A. De Lorenzo, MD, MSM, FACEP, ${ }^{2}$ and Steven W. Salyer, PA-C ${ }^{2}$
}

\begin{abstract}
During the Second Iraq War (Operation Iraqi Freedom), high-intensity, low-utilization medical and surgical services, such as neurosurgical care, were consolidated into a centralized location within the combat zone. This arrangement necessitated intra-theater air medical evacuation of critically ill or injured patients from outlying combat support hospitals (CSH) to another combat zone facility having the needed services. A case series is presented of intratheater transfer of neurosurgical patients in Iraq during 2005-06. Ninety-eight patients are included in the series, with typical transfer distances of 40 miles (approximately 20-25 minutes of flight time). All patients were transported with a CSH nurse in addition to the standard Army EMT-B flight medic. Seventysix percent of cases were battle injury, $17 \%$ were non-battle injuries, and the balance were classified as non-injury mechanisms. Seventy-six percent of cases were head injuries, with the balance involving burns, stroke, and other injuries. At 30 days, $12 \%$ of the patients had died, and $9 \%$ remained hospitalized in a critical care setting. None of the patients died during evacuation. Intratheater and interfacility transfer of critical care patients in the combat theater often involves severely head-injured and other neurosurgical cases. Current Army staffing for helicopter transport in these case requires a
\end{abstract}

1.C.R. Darnall Army Medical Center, Fort Hood, Texas

2. Brooke Army Medical Center, Fort Sam Houston, Texas

Address for correspondence:

Col Robert A. De Lorenzo, Department of Clinical Investigation, Brooke Army Medical Center, 3851 Roger Brooke Dr., Fort Sam Houston, TX 78234-6200,

Robert.DeLorenzo@amedd.army.mil

Acknowledgment

The authors thank Lieut. Colonel John Groves, head nurse, and all the physicians, nurses, medics of the 10th CSH emergency medical treatment section. Their dedication and professionalism were instrumental in the developing of this case series.

\section{Required Disclaimer}

The opinions or assertions are those of the authors and do not necessarily reflect those of the Army Medical Department or the Department of Defense.

$1067-991 X / \$ 36.00$

Copyright 2012 by Air Medical Journal Associates

http://dx.doi.org/10.1016/j.amj.2011.09.004 nurse or other advanced personnel to supplement the standard EMT-B flight medic.

\section{Introduction}

Helicopter transport was first used in World War II, and the first large-scale evacuation of wounded soldiers by helicopter took place during the Korean War. ${ }^{1}$ During the Vietnam War, the modern concept of air medical evacuation was first used on a large scale, and through these wartime experiences modern civilian air emergency medical services was born.

The military prefers the term evacuation, whereas the civilian community uses transport, but the concepts are interchangeable. The Army medical evacuation system comprises both ground and air evacuation platforms. The UH-60 Black Hawk helicopter is the dedicated airframe for Army evacuation. Other airframes such as the $\mathrm{CH}-47$ Chinook were also used, but this was infrequent. These airframes by design are rugged and capable; however, the medical staffing and equipment are limited by military doctrine. ${ }^{2}$

Wounded soldiers are treated within the limits of the combat medic (equivalent to EMT-B) at the point of injury or at a frontline aid station. After initial stabilization, they are evacuated by either ground or air ambulance to a Combat Support Hospital (CSH). ${ }^{3}$ If the distance to the $\mathrm{CSH}$ is far, the patient may first be evacuated to a Forward Surgical Team (FST) for resuscitative surgery before reaching the $\mathrm{CSH}$. If the injuries are severe, or a prolonged recovery is anticipated, the patient is flown to Europe and eventually evacuated to the United States aboard specially equipped United States Air Force evacuation aircraft configured as flying intensive care units (ICUs). ${ }^{4}$

An underlying premise of the military medical evacuation system is that the level of care increases as a wounded soldier is evacuated from the point of injury. However, anecdotal reports from the wars in Afghanistan and Iraq suggest continued challenges in achieving this goal during the transfer phase from an outlying CSH or FST to a more centrally located and capable CSH. Critical care patients being transferred from outlying facilities often require advanced-level care, and the standard medical staffing of Army helicopters may not fully match the needs of the patient. This case series highlights the issues of interfacility transfer in the combat zone and explores the types of patients transported and the medical staffing involved in the transport. 
Figure 1. Time Duration From Arrival at CSH to Transfer to Next Facility

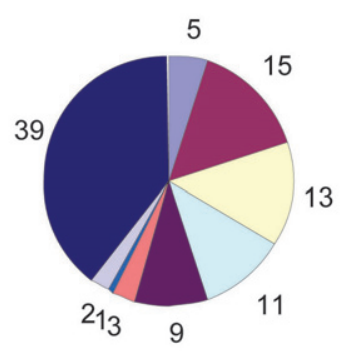

Figure 2. Interfacility Evacuations

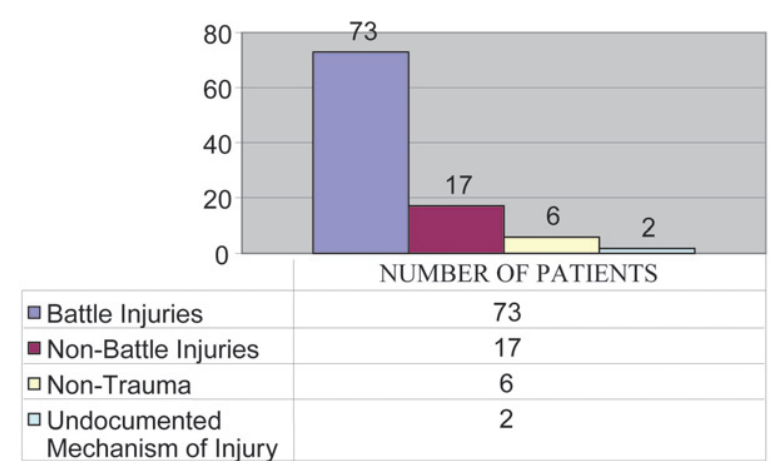

\section{Methods}

This is a nonconcurrent analysis of consecutive cases treated at the 10th CSH located in Baghdad and evacuated by air medical evacuation teams to another $\mathrm{CSH}$ within Iraq. The data source is case logs maintained by the transferring CSH emergency department (ED). These logs tracked 98 critically ill or injured patients requiring emergent air medical evacuation from the 10th CSH to another intratheater medical facility in Baghdad, Iraq, from December 2005 through September 2006. Most of these patients were acutely injured patients arriving directly from the point of injury. They received stabilizing treatment at the 10th CSH ED and required specialized care that was not available at the $10^{\text {th }} \mathrm{CSH}$. This case series does not include routine postoperative or ICU transfers. Outcomes were determined at approximately 30 days through follow-up information provided by institutions receiving the patients. Protocol approval was obtained by the Institutional Review Board of Brooke Army Medical Center, Fort Sam Houston, Texas.

\section{Results}

Ninety-eight patients were evacuated during the review period. All patients were evacuated in one of two different helicopter airframes: a UH-60 Black Hawk or a CH-47 Chinook helicopter. The evacuation distance by air for these patients was 40 miles (a 20-25-minute flight time in a combat environment). ${ }^{5}$ Flight crews varied depending on the airframe. At a minimum, the crew consisted of two pilots, one flight medic (trained to the basic emergency medical technician [EMT] level), and one maintenance crew chief. Because of the severity of injuries, a registered nurse from the 10th $\mathrm{CSH}$ accompanied each evacuated patient. ${ }^{5}$

The amount of time spent at the 10th $\mathrm{CSH}$ from initial arrival until transfer was available for 59 of the 98 evacuated patients and is shown in Figure 1. Data collection for the patient log began in December 2005; collection of the "time spent on site" data did not begin until March 2006.

Figure 2 shows the distribution of battle and nonbattle injuries. This distribution is important to the military for administrative purposes and is defined explicitly. ${ }^{6}$ Tables 1 and 2 show the breakdown by specific injury or illness. Figures 3 and 4 describe outcomes and causes of death.

Thirty-day follow-up information was available on 98\% of these patients evacuated to a higher level of care. At 30 days, $12 \%$ of the patients had died, and 9\% remained hospitalized in a critical care setting. None of these patients died during evacuation (Figs. 3 and 4).

\section{Discussion}

Our case series suggests that emergency interfacility transfer of patients was relatively common in the Iraqi theater in 2005 to 2006. Nearly 100 patients were transferred in a 10month period from a single site (there were typically 3 to 4 $\mathrm{CSH}$ in Iraq). Local conditions, including the rate of patients produced by the war and the geographic location of the point of injury, can affect the incidence of transfers. In our case series, the primary reason for transfer appears to be related to the lack of certain types of specialty care at the $10^{\text {th }} \mathrm{CSH}$. In particular, the lack of neurosurgical capability was the main reason for transfer of $88(90 \%)$ of the patients transferred. At the time of the study, only one CSH in Iraq had neurosurgeons on staff and a fully-capable neurosurgical ICU.

The evacuations in this series were not scheduled; they were urgent evacuations of critically ill or injured patients from the ED. These patients required intensive en route critical care to include constant monitoring of vital signs, manual or mechanical ventilation, and maintenance of intravenous fluids and administration of necessary intravenous medications for sedation and the treatment of elevated intracranial pressure and seizures. Most patients spent less than 2 hours in the ED before transfer, and thus their clinical stability was not always assured; however, a significant number of cases had undocumented times, limiting this interpretation.

Information from other sources shows that the procedures performed most commonly while in flight are intubation, airway management, and intravenous access. ${ }^{7}$ Other commonly performed in-flight patient care interventions and procedures include oxygen administration, spinal immobilization, splinting and dressing, and cardiopulmonary resuscitation. ${ }^{8}$ 
Table 1. Injury Categories

\begin{tabular}{lc}
\hline Battle Injuries & $\mathbf{7 3}$ \\
\hline Head trauma (5 with multi trauma) & 57 \\
Spinal trauma (1 with multi trauma) & 5 \\
Other trauma (6 with associated head or spinal trauma) & 10 \\
Undocumented injuries & 1 \\
Non-Battle Injuries & $\mathbf{1 7}$ \\
\hline Head trauma (one with associated infection) & 10 \\
Spinal trauma & 6 \\
Other trauma & 0 \\
Undocumented injuries & 1 \\
Nontraumatic Diagnosis Requiring Evacuation & $\mathbf{6}$ \\
\hline Acute myocardial infarction & 2 \\
Hydrocephalus & 1 \\
Seizure & 1 \\
Stroke & 1 \\
Subarachnoid hemorrhage & 1
\end{tabular}

2 patients with undocumented mechanisms of injury with "other" trauma

The First Iraq War (Operations Desert Shield and Desert Storm) unmasked several medical issues in which the U.S. military had fallen behind civilian systems of injury care. ${ }^{9}$ Among the issues highlighted was the level of medical attendant accompanying wounded patients. By the mid-1990s, the standard civilian air evacuation model included staffing by a paramedic or a critical care nurse. The Army staffing model, however, still relied on the Vietnam-era model of a combat medic trained to the EMT-B level. A 1997 paper reviewed the issue and recommended that "advanced training for flight medics and improved lifesaving equipment be considered standard."10 A follow-on report in 2000 focused on a large Army helicopter program and concluded that $35 \%$ of trauma and $11 \%$ of nontrauma patients were transported by an EMTB combat medic when a higher level of care was indicated. ${ }^{8}$ The data in the current series indicate that the helicopter medical staffing situation had not appreciably changed in the intervening decade.

To address the perceived interfacility transfer capability gap, a number of initiatives were proposed and initiated. In 1994, after Gulf War I, the Air Force developed mobile critical care teams called Critical Care Aeromedical Transport teams in response to an unmet military need for long-range air evacuation of critically ill and injured patients. ${ }^{11}$ The teams usually consist of an intensivist physician, a critical care nurse, and a respiratory therapist. ${ }^{12}$ This solved the "out of the war zone" evacuation of critical patients, but did not address the interfacility or intratheater evacuation of patients, most of who were still transferred with a single EMT-B combat medic in attendance.

On a local level, field hospitals responded by placing nurses on the helicopters, but this degraded the already stretched CSH staff because it could take days to repatriate
Table 2. Injuries Sustained (Other than Head or Spinal)

\begin{tabular}{ll}
\hline Facial & 9 \\
Eye & 2 \\
Torso & 3 \\
Extremity & 3 \\
Burns not otherwise specified (NOS) & 1 \\
Shrapnel NOS & 1 \\
Fracture NOS & 1 \\
Multiple fractures NOS & 1 \\
Multiple injuries NOS & 1 \\
\hline
\end{tabular}

the nurses from the receiving hospital back to their assigned hospital. Of note, the nurses in this series received no formal flight training, and the critical care equipment had to be loaded and unloaded off the helicopter for each mission.

In an attempt to address these gaps, the Army implemented a new training program on en route care, the Joint Enroute Care Course, in 2005. The approach was to train nurses and other medical personnel at the CSH to perform the interfacility evacuations. This bridged the gap for the transported patient but did not address the underlying issue of consuming scarce CSH resources to accomplish an evacuation mission. It also did not resolve the problem for FSTs. These far-forward surgical units are very thinly staffed and cannot afford to loan even a single nurse without suffering significant degradation of capability.

Remarkably, the Army recently embarked on a bold initiative to train all Army flight medics to the level of EMTparamedic. ${ }^{13}$ Flight medics would also be certified as critical care flight paramedics. Once fully implemented, this initiative will substantially bridge the interfacility transfer care gap in the Army air medical system, because every medical helicopter will have a crewmember capable of managing critical care patients.

With plans in place to improve the capability of the medical attendant on Army helicopters, future studies will be needed to evaluate how this additional training has improved the care of and outcomes for the wounded. Additional studies also may help assess whether these changes will bring parity in medical staffing and capability in comparison with civilian programs.

\section{Limitations}

This is a case series reviewing evacuations conducted from a single site during a 10-month period. This series was conducted through a log review and not a complete medical records analysis. It focused on emergent evacuations of ED patients requiring additional interventional care. This study did not review the thousands of "routine" evacuations that included stabilized postoperative patients or patients already admitted to the ICU. Additionally, this series did not include the initial ground or air evacuation of wounded patients from their point of injury. This analysis did not provide specific 
Figure 3. Patient Outcomes

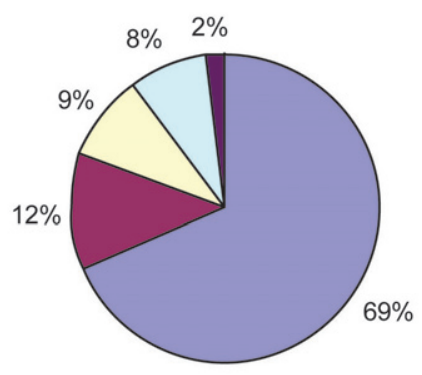

Figure 4. Causes of Death

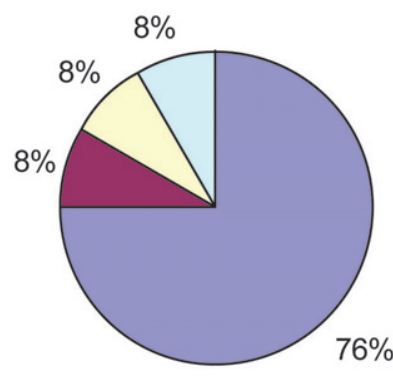

$\square$ Head Injury

- Burns

$\square$ Stroke

$\square$ Undocumented Injuries information on in-flight patient care or emergent interventions that were performed while en route. It also did not analyze the details of whether the medical personnel were specifically trained in air medical evacuation, critical care, or whether they had attended the Joint Enroute Care Course.

\section{Conclusion}

Intratheater and interfacility transfer of critical care patients in the combat theater often involves severely headinjured and other neurosurgical cases. Current Army staffing for helicopter transport in these case requires a nurse or other advanced personnel to supplement the standard EMT-B flight medic. 